\title{
Healing of localized gingival recessions treated with a coronally advanced flap alone or combined with an enamel matrix derivative and a porcine acellular dermal matrix: a preclinical study
}

\author{
Y. Shirakata ${ }^{1}$ A. Sculean ${ }^{2} \cdot$ Y. Shinohara ${ }^{1} \cdot$ K. Sena ${ }^{1} \cdot$ N. Takeuchi ${ }^{1} \cdot$ \\ D. D. Bosshardt ${ }^{2,3} \cdot$ K. Noguchi ${ }^{1}$
}

Received: 23 June 2015 / Accepted: 22 November 2015 /Published online: 27 November 2015

(C) Springer-Verlag Berlin Heidelberg 2015

\begin{abstract}
Objective This study aimed to evaluate the effects of a porcine acellular dermal matrix (PADM) with or without an enamel matrix derivative (EMD) on gingival recession defects treated with a coronally advanced flap (CAF) in dogs.

Materials and methods Miller class II gingival recession defects (5 $\mathrm{mm}$ wide and $7 \mathrm{~mm}$ deep) were surgically created on the labial side of bilateral maxillary canines in 12 dogs. After 8 weeks of plaque accumulation, the 24 chronic defects were randomly assigned to one of the following 4 treatments: CAF, CAF with PADM (CAF/PADM), CAF with EMD (CAF/ EMD), and CAF with EMD and PADM (CAF/EMD/ PADM). The animals were sacrificed 10 weeks after surgery for histologic evaluation.

Results In all groups, root coverage was obtained to a varying degree. PADM was well incorporated in gingival connective tissue in the CAF/PADM and in the CAF/EMD/PADM groups. The height of newly formed bone was significantly greater in the CAF/EMD/PADM group than in the CAF and CAF/PADM groups. New cementum with periodontal ligament-like tissue was predominantly found in the $\mathrm{CAF} /$
\end{abstract}

Y. Shirakata

syoshi@dent.kagoshima-u.ac.jp

1 Department of Periodontology, Kagoshima University Graduate School of Medical and Dental Sciences, 8-35-1, Sakuragaoka, Kagoshima 890-8544, Japan

2 Department of Periodontology, School of Dental Medicine, University of Bern, Bern, Switzerland

3 Department of Oral Surgery and Stomatology, School of Dental Medicine, University of Bern, Bern, Switzerland
EMD and CAF/EMD/PADM groups. The CAF/EMD/ PADM group showed the greatest amount of new cementum among the groups examined, although the difference was not statistically significant.

Conclusion Within the limitations of the present study, it can be concluded that CAF/EMD/PADM treatment may promote periodontal regeneration in gingival recession defects.

Clinical relevance The present results suggest that the combination of EMD and PADM in conjunction with CAF may represent a promising approach for treating single Miller class II gingival recessions.

Keywords Root coverage - Gingival recession defects . Porcine acellular dermal matrix - Enamel matrix derivative . Periodontal regeneration $\cdot$ Animal study

\section{Introduction}

Gingival recession causes many problems such as impaired aesthetics, plaque accumulation, and subsequent gingivitis and/or root caries or dentin hypersensitivity [1,2]. A variety of surgical techniques has been developed to predictably obtain complete root coverage of gingival recession defects [3]. Clinically, the subepithelial connective tissue graft (CTG) in conjunction with a coronally advanced flap (CAF) is considered to be the gold standard due to its favorable outcomes for root coverage [2, 3]. However, major shortcomings of harvesting CTG are patient morbidity associated with the second surgical site and surgical time, as well as the limited supply of donor tissue especially for treating multiple recession defects $[4,5]$. Thus, the acellular dermal matrix (ADM) allograft has been introduced to overcome these drawbacks [6]. Histological and clinical studies have shown that ADM and 
CTG may result in comparable outcomes when used in conjunction with CAF for recession coverage [6-9]. It has been reported that healing following ADM placement is characterized by minimal creeping attachment, connective tissue adhesion, and limited blood supply for graft integration [10-12]. Moreover, due to its human origin and the potential risk of disease transmission or psychological aspects, the ADM is still controversially discussed in some countries [13]. In order to overcome the drawbacks related to the use of human cadaveric dermal tissues, various types of collagen matrices have been introduced. Very recent preclinical and clinical studies have provided evidence for the effectiveness of a porcine-derived collagen matrix in the treatment of single or multiple gingival recessions [5, 14-19]. Further studies have shown that a porcine-derived acellular dermal collagen matrix (PADM: Mucoderm ${ }^{\circledR}$, Botiss Dental, Berlin, Germany) can promote growth and proliferation of human gingival fibroblasts, osteoblasts, and endothelial cells in vitro, while in vivo findings have revealed that PADM is capable of significant revascularization of its collagen structure during the early healing period $[13,20,21]$.

The ultimate goal of root coverage treatment is not only to cover the gingival defects but also to regenerate periodontal supporting apparatus (cementum, periodontal ligament, and alveolar bone) for maintaining the obtained gingival height and width. Enamel matrix derivative (EMD) was first documented in the periodontal literature in 1997 as a tissue healing modulator to mimic events that occur during root development. It is an effective agent for stimulating periodontal regeneration with formation of a new acellular extrinsic fiber cementum, which firmly attaches to the denuded root surface $[22,23]$. Moreover, it has recently been demonstrated that EMD has a positive influence on the increase in gingival thickness in dehiscence-type defects in dogs [24]. These results might propose a new rationale for the increased predictability of CAF in achieving complete root coverage when EMD and/or PADM is used adjunctively.

Therefore, the present study aimed to evaluate the effects of a PADM with or without EMD on gingival recession defects treated with CAF in dogs.

\section{Method and materials}

\section{Animals}

Twelve healthy male Beagle dogs, 11 to 15 months old, weighting 10.3 to $14.4 \mathrm{~kg}$, were used in this study. The procedures and protocol design described here were approved by the ethical committee of the Animal Research Center of Kagoshima University, Japan (MD13164).

\section{EMD}

Emdogain ${ }^{\circledR}$-Gel (Straumann, Basel, Switzerland), a premixed ready-to-use heat-treated Emdogain ${ }^{\circledR}$ dissolved in a propylene glycol alginate (PGA) solution, was used.

\section{PADM}

Porcine acellular dermal matrix (PADM: Mucoderm ${ }^{\circledR}$, Botiss Dental, Berlin, Germany) is a collagen tissue matrix derived from porcine dermis that passes through a multi-step cleaning process which removes all antigenic components from the dermis. This results in a three-dimensional stable matrix consisting of type I/III collagen and elastin.

\section{Surgical protocol}

One surgeon (Y.S.) performed all surgical procedures under general and local anesthesia using aseptic routines. General anesthesia was achieved using sodium pentobarbital $(0.4 \mathrm{ml} / \mathrm{kg}$ IV; Somunopenchiru, Kyoritsu Seiyaku, Tokyo, Japan) maintaining spontaneous breathing. Local anesthesia was performed using lidocaine $\mathrm{HCl} /$ epinephrine ( $2 \%, 1: 80,000$; Xylocaine). Dehiscencetype gingival recession defects were surgically created bilaterally in the maxillary canines. Two vertical incisions separated by a distance of $5 \mathrm{~mm}$ were made from the gingival margin and extending $7 \mathrm{~mm}$ apically. These incisions were connected apically by a horizontal incision and coronally by an intrasulcular incision. The gingival tissue limited by the incisions was removed using a periosteal elevator. The exposed bone was removed by hand instruments and the root surface instrumented to remove the cementum. A coronal notch extending $5 \mathrm{~mm}$ in the mesio-distal direction was placed on the root surface at the level of the cemento-enamel junction (CEJ). The created defects were exposed for a period of 8 weeks to plaque accumulation (Fig. 1a). After 8 weeks of plaque accumulation, scaling and root planing were performed. A regimen of plaque control using a $2 \%$ solution of chlorhexidine gluconate was instituted for 14 days prior to the reconstructive surgeries. Fullthickness flaps were then raised; the root surfaces were once again scaled. Additional reference notches were made using a \#1 round bur on the root surface at the base of the defects, and on the crown surface to indicate the precise center plane of the dehiscence defects and to aid in optimal histologic processing (Fig. 1b). Each of the contralateral defects in each animal was then randomly assigned to one of the following treatments: CAF alone, CAF with EMD (CAF/EMD), CAF with PADM placement (CAF/PADM), and their combination (CAF/ $\mathrm{EMD} / \mathrm{PADM}$ ). In the CAF/PADM group, PADM was 
Fig. 1 Clinical overview. a Fabricated dehiscence type of gingival recession defect after 8 weeks of plaque accumulation. b Defect on the root after flap elevation. c EMD was applied onto the denuded root surface after root conditioning. d PADM was placed to cover the entire defect and the adjacent bone and sutured. e A coronally advanced flap totally covered the PADM. f At 10 weeks after root coverage of canine treated by CAF with EMD and PADM. Healing was uneventful
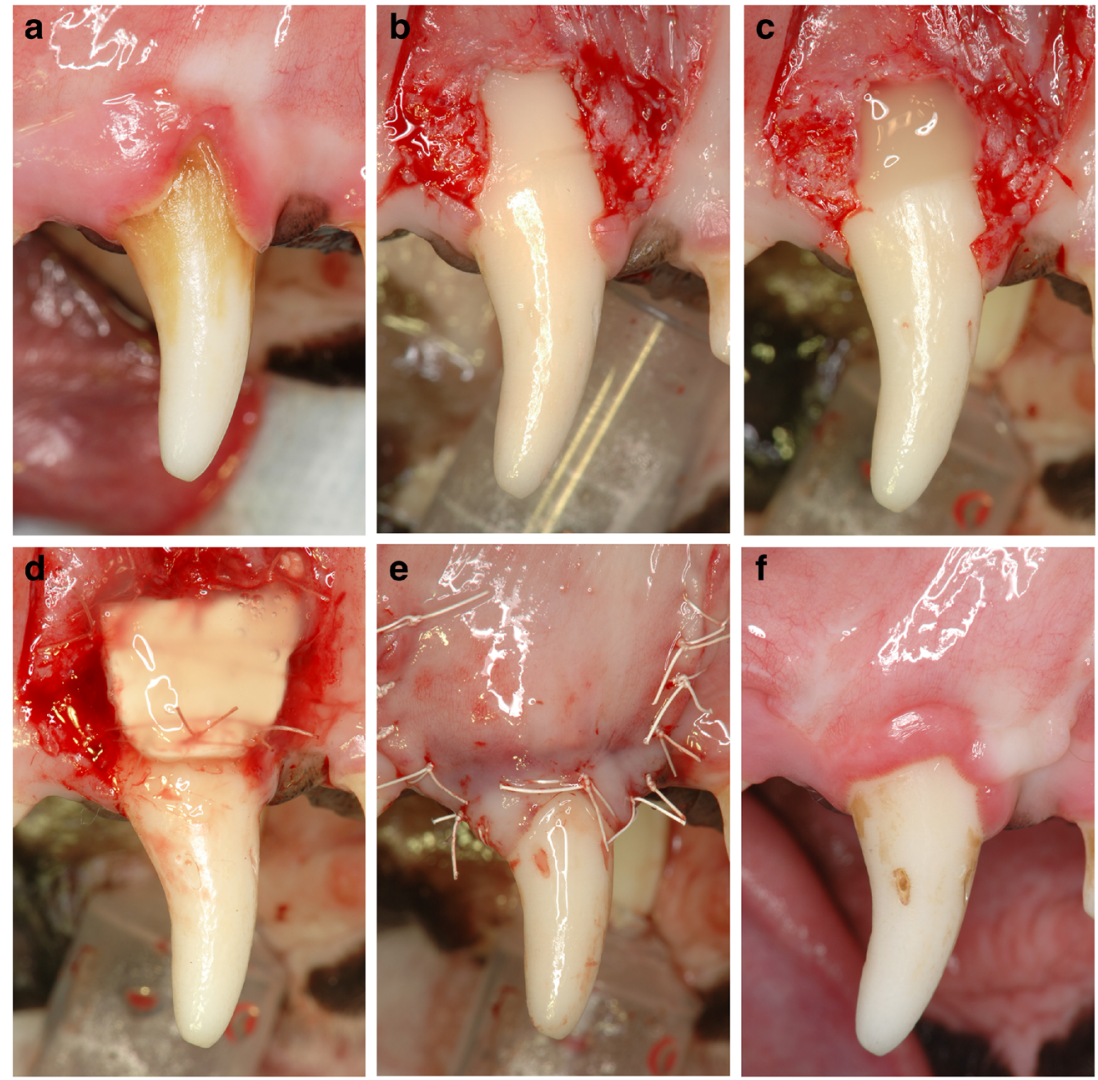

mixed with the animal's fresh blood for $10 \mathrm{~min}$ before being applied to the defect. Defect root surfaces that received EMD were conditioned with a $24 \%$ EDTA gel (PrefGel ${ }^{\circledR}$, Straumann AG, Basel, Switzerland) for 2 min and then, along with the adjacent mucoperiosteal flaps, thoroughly rinsed with sterile saline. The EMD gel was applied to the root surfaces, and the defects were filled up to the adjacent alveolar crest (Fig. 1c). Prior to the placement of EMD/PADM, the PADM was trimmed and fully saturated with the EMD gel and the construct was allowed to rest for $10 \mathrm{~min}$. The construct (EMD/PADM) was placed over the denuded root surfaces. The PADM was fixed to the residual periosteum using resorbable 5-0 sutures to cover the gingival recession defects completely (Fig. 1d). A periosteal releasing incision was made, and the reflected gingival flaps were coronally advanced to the pretreatment position, attempting to fully cover the defects and/or PADM, and sutured using monofilament suture material (Gore-Tex CV-6 Suture) (Fig. 1e).

The animals were fed a soft diet for 2 weeks. An analgesic of buprenorphine $\mathrm{HCl}(0.1 \mathrm{ml} / \mathrm{kg} \mathrm{IM}$; Lepetan $)$ and an antibiotic (Procaine penicillin G, 200,000 units IM) were administered daily for 3 days. Plaque control was maintained by routine flushing (three times a week) of the oral cavity with a chlorhexidine solution (chlorhexidine gluconate; $25 \mathrm{ml}$ of a
$2 \%$ solution) for 10 weeks postsurgery. The sutures were removed 2 weeks after surgery.

\section{Histologic and histometric analyses}

Ten weeks after surgery, the animals were euthanized by an overdose injection of sodium pentobarbital. All the defects were dissected along with the surrounding soft and hard tissues. The tissue blocks were fixed in $10 \%$ buffered formalin and trimmed. The samples were dehydrated and embedded in polyester resin. The resin blocks were cut bucco-lingually to a thickness of 100 to $150 \mu \mathrm{m}$ with a low-speed diamond saw. Slides were ground and polished to a final thickness of 35 to $45 \mu \mathrm{m}$ using a microgrinding system with non-adhesive abrasive discs and stained with toluidine blue. All the specimens were analyzed histometrically under a light microscope (BX51, Olympus Optical Co., LTD, Tokyo, Japan) equipped with a computerized image system (Win Roof Version 6.0, Mitani Corporation, Fukui, Japan). For histometric analysis, two sections were selected from the most central area of each gingival recession defect, identified by the coronal and apical notches on the root and the reference notch on the crown. The mean value of each histometric parameter was calculated for each site. 
The following parameters were measured by the same experienced and masked examiner (N.T.):

1 Gingival recession (GR) - distance from the gingival margin to the coronal notch (CEJ) at the sites where the gingival margin was located apically to the coronal notch. Negative values were assigned to these measurements. If the gingival margin was located at the level of the coronal notch or coronal to this notch, a " 0 " value was applied.

2 Epithelial length (EL) - distance between the apical extent of junctional epithelium and the coronal notch when the gingival margin was coronal to the coronal notch. If gingival recession was present, this measurement was recorded from the gingival margin to the apical extent of junctional epithelium.

3 Connective tissue adaptation (CT; without cementum) distance between the apical extent of junctional epithelium and coronal extent of newly formed cementum.

4 New cementum formation (NC) - distance between the apical extent of root planing and the coronal extent of newly formed cementum on denuded root surface.

5 New bone formation (NB) - distance between the apical extent of root planing and the coronal extent of newly formed alveolar bone.

6 Soft tissue thickness (STT) - distance from the buccal outermost gingival/mucosal surface to the tooth surface at three different levels:

(a) STT-1 - at the top of the coronal notch (CEJ)

(b) STT-2 - at the middle between the coronal and apical notches

(c) STT-3 - at the base of the apical notch (defect)

7 Soft tissue height (STH) - distance between the apical extent of root planing and the gingival margin.

8 Defect height (DH) - distance between the apical notch and the coronal notch.

Forty-eight sections from all sites were read by the examiner without calibration before the measurements. Forty-eight hours later, the same examiner read all 48 sections again to evaluate intra-examiner reproducibility. Inter-calibration of the examiner was accepted at the $90 \%$ level.

\section{Statistical analysis}

Mean values for each histometric parameter were obtained per defect. The mean values for all groups were determined using the individual means from the 12 animals. The hypothesis that there were no differences among the groups was tested by analysis of variance. If a statistical difference was detected, a post hoc test was used for multiple comparisons. A $p$ value of $<0.05$ was considered statistically significant. All calculations were performed using a statistical software program (SPSS Statistics Version 20, IBM, Armonk, NY, USA).

\section{Results}

\section{Clinical observations}

Root coverage was obtained to a varying degree in this chronic gingival recession model. Basically, the gingival margin was located approximately at the CEJ in all sites. Residual gingival recessions (the gingival margin was located below the CEJ) were found in four sites in the CAF group, two sites in the CAF/EMD group, and one site in the CAF/PADM and CAF/EMD/PADM groups. One site in the CAF/EMD/PADM group was excluded from histologic and histometric analyses because of severe dehiscence of the flap with considerable PADM exposure due to physical contact of the lower canine 3 days after surgery. The rest of the five sites in the CAF/ EMD/PADM group exhibited favorable clinical healing without any complications (Fig. 1f).

\section{Histologic observations}

In the CAF group, slight gingival recession remained in most of the specimens (four sites) (Fig. 2a). The amount of new bone was minimal and new cementum formation was very limited above the apical notch in a few specimens. Periodontal regeneration was not observed in most of the specimens, and connective tissue fibers were aligned parallel to the root surface (Fig. 2a, b). In the $\mathrm{CAF} / \mathrm{PADM}$ group, the residual gingival recession was detected only in one site, and the amounts of soft tissue height and soft tissue thickness were greater compared to those of the CAF group (Fig. 3a). In general, the healing pattern regarding new bone and orientation of collagen fibers in the CAF/PADM group was similar to that in the CAF group. However, a thin continuous layer of new acellular extrinsic fiber cementum was predominantly detected on the previously denuded and contaminated root surface in four sites (Fig. 3b). In the PADM-applied groups (CAF/PADM, CAF/EMD/PADM), remnants of the PADM were found to varying degrees and they were completely integrated with the adjacent connective tissue with no signs of encapsulation, multinucleated giant cells, or granulation tissue (Figs.3b and $6 \mathrm{a}, \mathrm{b}$ ).

New bone was observed coronally to the apical notches in most of the specimens (five sites) in the CAF/EMD and CAF/EMD/PADM groups. Moreover, a thin continuous layer of a blend of new cellular, intrinsic, or mixed fiber cementum was mostly found at the apical portion and tended to change to acellular extrinsic fiber cementum at 
Fig. 2 Representative photomicrographs of a gingival recession defect treated by CAF. a Overview of the defect (scale bar, $1 \mathrm{~mm}$; toluidine blue staining). $\mathbf{b}$ Higher magnification of the notch area (scale bar, $200 \mu \mathrm{m}$; toluidine blue staining). $C E J$ cementoenamel junction, $G M$ gingival margin, $D$ root dentin, $J E$ apical end of junctional epithelium, $N$ apical end of apical notch

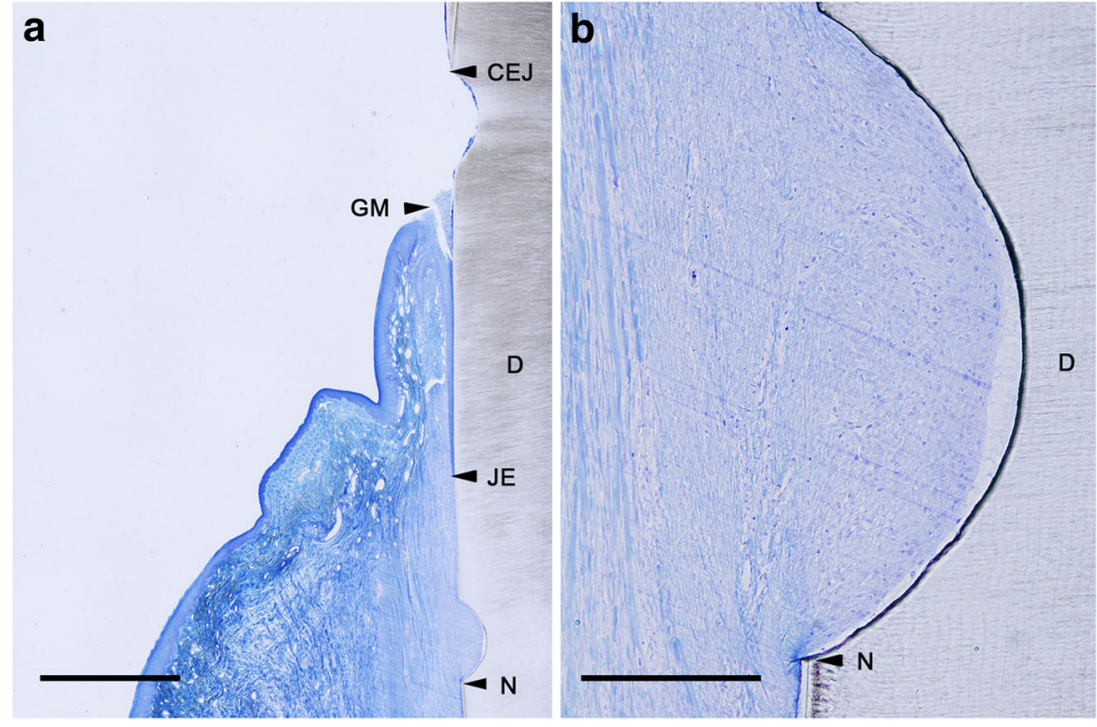

the coronal portion on the denuded root surface in these EMD-applied groups (Figs. 4, 5, and 6). Dense collagen fibers were seen inserting into the newly formed cementum, oriented oblique to the root surface (Figs. 4b and 6a, b). However, bone formation was more pronounced in the CAF/EMD/PADM group than in the CAF/EMD group (Fig. 5). There was no extensive root resorption or ankylosis, irrespective of the treatment group.

\section{Histometric analysis}

The results of the histometric analysis are summarized in Table 1 . No statistically significant differences were detected among the groups in regard to the following measurements: GR, EL, CT, STT-3, and DH. New cementum formation with continuous periodontal ligament-like tissue was most notable in the CAF/EMD/PADM group among the groups examined, although the difference was not statistically significant. More cementum was also found in the CAF/EMD group compared to both the CAF and CAF/ PADM groups, although without statistically significant differences. New bone formation in the CAF/EMD/PADM group was significantly greater than in the CAF and CAF/PADM groups. In the CAF/EMD/PADM group, soft tissue thickness at the top of the notch was significantly greater than that in the CAF group. Moreover, soft tissue thickness at the middle between the coronal and apical notches was significantly greater in the CAF/EMD/PADM group than in both the CAF and CAF/PADM groups. For soft tissue height, there were no significant differences
Fig. 3 Representative photomicrographs of a gingival recession defect treated by $\mathrm{CAF}$ with PADM. a Overview of the defect (scale bar, $1 \mathrm{~mm}$; toluidine blue staining). b Higher magnification of the middle portion of the defect (scale bar, $200 \mu \mathrm{m}$; toluidine blue staining). $C E J$ cemento-enamel junction, $G M$ gingival margin, $D$ root dentin, $J E$ apical end of junctional epithelium, $N$ apical end of apical notch, $N C$ new cementum, * remnants of PADM. Fiber bundles of the PADM were dispersed and surrounded by connective tissue
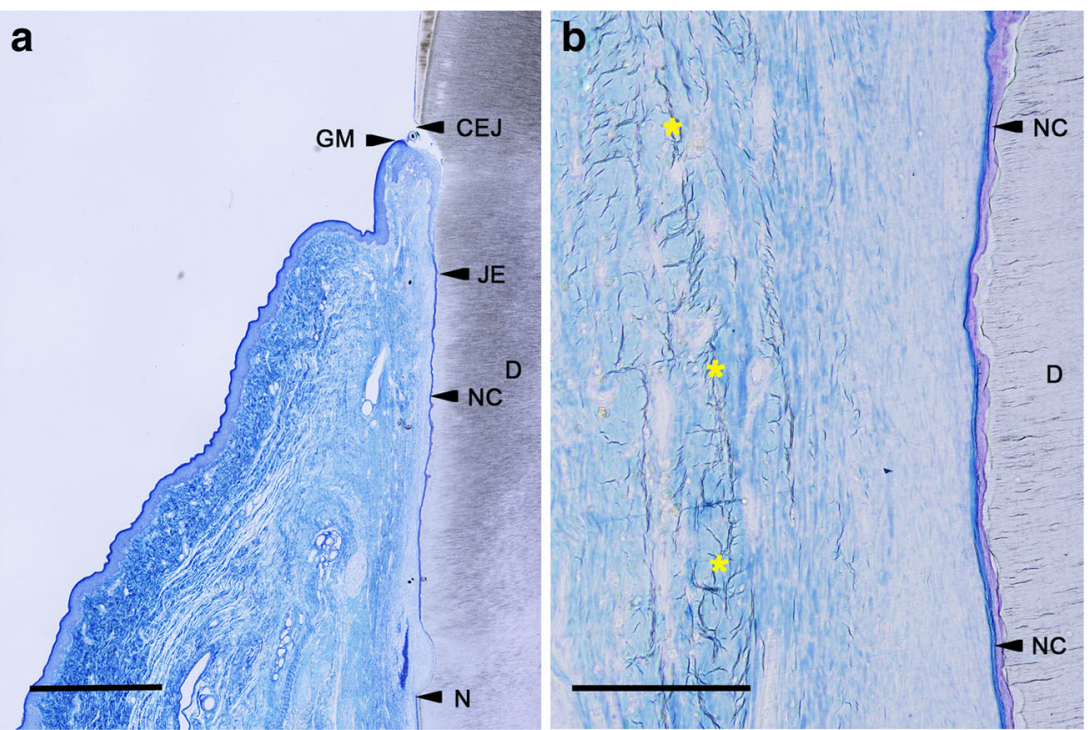
Fig. 4 Representative photomicrographs of a gingival recession defect treated by $\mathrm{CAF}$ with EMD. a Overview of the defect (scale bar, $1 \mathrm{~mm}$; toluidine blue staining). b Higher magnification of the notch area (scale bar, $200 \mu \mathrm{m}$; toluidine blue staining). $C E J$ cemento-enamel junction, $G M$ gingival margin, $D$ root dentin, $J E$ apical end of junctional epithelium, $N$ apical end of apical notch, $N B$ new bone, $N C$ new cementum, $P D L$ periodontal ligament
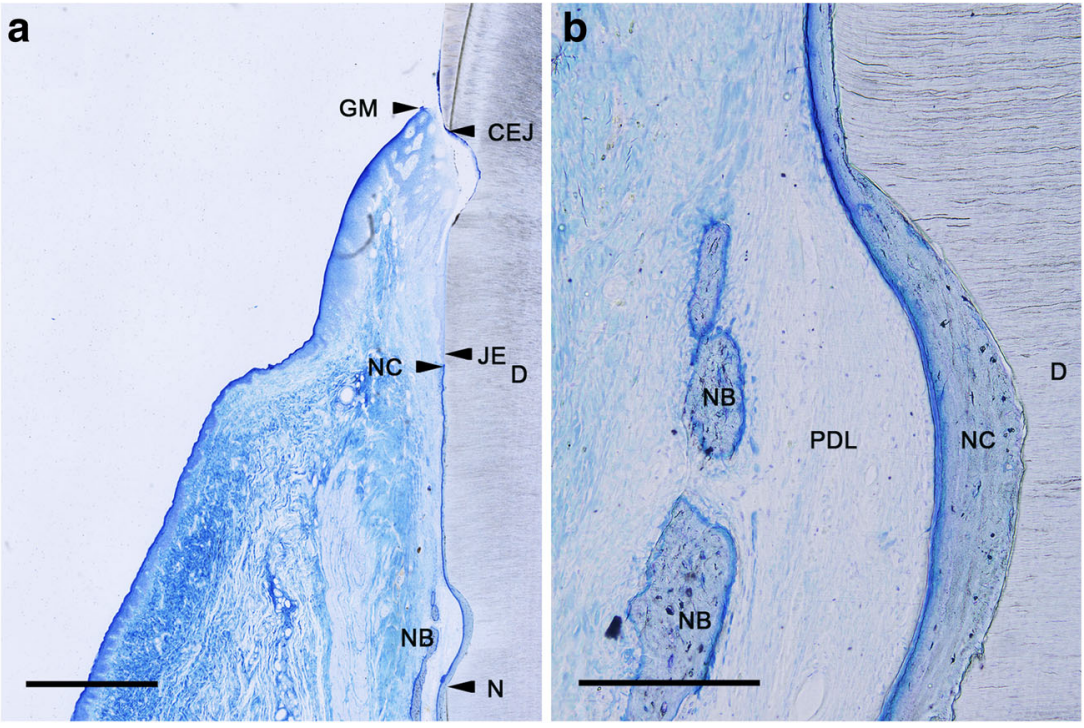

among the groups. Nevertheless, the CAF group showed the smallest height and the CAF/EMD/PADM group showed the greatest height. No significant differences in any of the histometric parameters were observed between the $\mathrm{CAF} / \mathrm{EMD}$ and $\mathrm{CAF} / \mathrm{EMD} / \mathrm{PADM}$ groups.

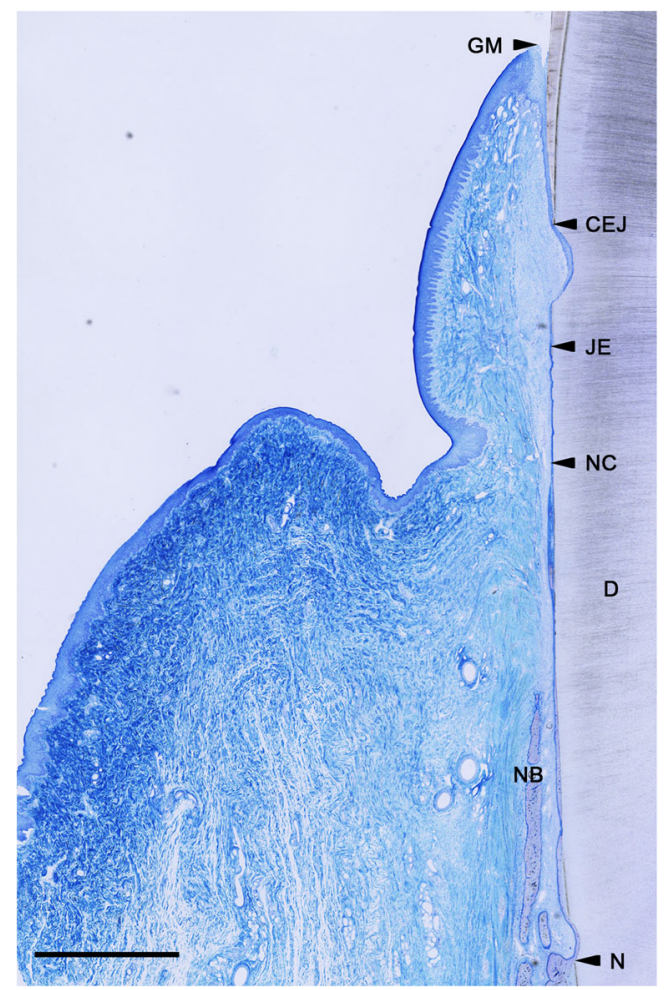

Fig. 5 Representative photomicrograph of a gingival recession defect treated by CAF with EMD and PADM. Overview of the defect (scale bar, $1 \mathrm{~mm}$; toluidine blue staining). CEJ cemento-enamel junction, $G M$ gingival margin, $D$ root dentin, $J E$ apical end of junctional epithelium, $N$ apical end of apical notch, $N B$ new bone, $N C$ new cementum

\section{Discussion}

To the best of our knowledge, no preclinical study has yet evaluated the outcomes of a CAF, CAF with PADM $\left(\right.$ Mucoderm $\left.^{\circledR}\right)$, and/or EMD for the treatment of gingival recessions. The present study shows that CAF/EMD/PADM resulted to a greater extent in periodontal regeneration than the other treatment groups. The amount of newly formed cementum was greater in the EMD-applied groups (CAF/EMD and $\mathrm{CAF} / \mathrm{EMD} / \mathrm{PADM}$ ) than in the CAF and CAF/PADM groups. These findings are in agreement with previous reports demonstrating that EMD deposition on the root surfaces potently affects cementum formation [22, 25]. Moreover, dense collagen fibers inserted into the newly formed cementum were oriented obliquely to the root surface. Highly vascularized new periodontal ligament-like tissue was found only in the area between new cementum and new bone in the EMDapplied groups. These findings are similar to those of previous studies evaluating the effect of EMD on the healing of various periodontal defects [22-27]. These results may be explained by the report that EMD significantly promotes both periodontal ligament and bone cell attachment [28], and stimulates angiogenesis directly through endothelial cells and indirectly through production of vascular endothelial growth factor by periodontal ligament cells $[29,30]$.

In this chronic dehiscence defect model, the buccal alveolar bone plate was very thin (generally $<1 \mathrm{~mm}$ ) at the reconstructive surgery due to bone resorption. It has been reported that the space between the flap and the root surface was minimal resulting in the small amounts of newly formed bone or root resorption following root coverage treatments using guided tissue regeneration, EMD, ADM, CTG, or platelet-rich plasma [31-35]. The amount of new bone obtained in the present study was comparable to that of previous reports. However, 
Fig. 6 a Higher magnification of the middle portion of newly formed bone seen in Fig. 5 (scale bar, $200 \mu \mathrm{m}$; toluidine blue staining). b Higher magnification of the coronal extent of newly formed bone seen in Fig. 5 (scale bar, $200 \mu \mathrm{m}$; toluidine blue staining). $C E J$ cemento-enamel junction, $D$ root dentin, $J E$ junctional epithelium, $N$ apical notch, $N B$ new bone, $N C$ new cementum, $P D L$ periodontal ligament, * remnants of PADM
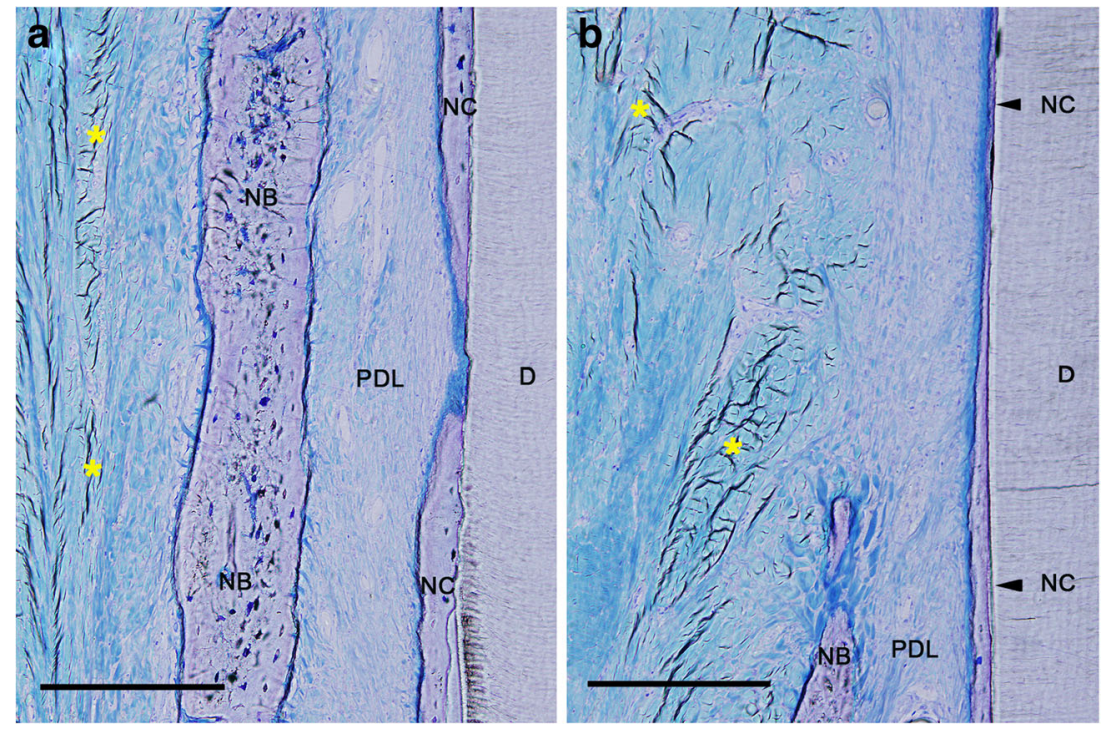

the CAF/EMD/PADM group induced significantly greater bone formation with narrow bone growth along the root surface compared to the CAF and CAF/PADM groups. The results are supported by the findings that new bone formation occurs moderately along the root surface following acellular cementum and periodontal ligament formation [25, 27, 36], and indicate that EMD improved bone formation in gingival recession defects treated by CAF or CAF/PADM. Sallum et al. reported that the extent of new bone and new cementum was greater with $\mathrm{CAF} / \mathrm{EMD}$ treatment than with $\mathrm{CAF}$ treatment alone, although the differences were not statistically significant [32]. Moreover, an earlier study demonstrated that the amounts of new cementum and new bone at the sites of gingival recession were significantly greater after CAF with EMD and GTR treatment than those after CAF and GTR or
CAF treatment [37]. These results indicate that EMD has adjunctive biological effects on the formation of both new cementum and new bone and PADM may act as a biocompatible barrier membrane to provide sufficient space maintaining its three-dimensional structure for cell migration and growth [13, 20], blood clot stabilization $[38,39]$ as well as new tissue formation in this type of dehiscence defects. However, it might be necessary to compare CAF/EMD/PADM and CAF/ EMD/GTR in the same type of defects to investigate whether PADM has indeed an additional role as a barrier membrane.

In contrast, de Oliveira et al. demonstrated that EMD did not result in beneficial effects regarding new cementum and new bone when combined with ADM compared to ADM alone [33]. The discrepancy in bone and cementum formation between our study and the study by de Oliveira et al. [33] may

Table 1 Histomorphometric parameters for each surgical treatment (mean $\pm \mathrm{SD} ; \mathrm{mm}$ )

\begin{tabular}{|c|c|c|c|c|c|}
\hline & \multicolumn{4}{|c|}{ Surgical treatment } & \multirow{2}{*}{$\begin{array}{l}\text { Statistically } \\
\text { significant } \\
\text { differences }\end{array}$} \\
\hline & $\begin{array}{l}\text { (1) CAF } \\
n=6\end{array}$ & $\begin{array}{l}\text { (2) CAF/EMD } \\
n=6\end{array}$ & $\begin{array}{l}\text { (3) CAF/PADM } \\
n=6\end{array}$ & $\begin{array}{l}\text { (4) } \mathrm{CAF} / \mathrm{EMD} / \\
\mathrm{PADM} \\
n=5\end{array}$ & \\
\hline GR & $-0.55 \pm 0.62$ & $-0.07 \pm 0.11$ & $-0.09 \pm 0.21$ & $-0.15 \pm 0.34$ & NS \\
\hline EL & $2.79 \pm 0.62$ & $2.31 \pm 0.95$ & $2.15 \pm 1.33$ & $2.16 \pm 0.92$ & NS \\
\hline $\mathrm{CT}$ & $0.45 \pm 0.74$ & $0.60 \pm 0.99$ & $0.66 \pm 1.08$ & $0.42 \pm 0.41$ & NS \\
\hline $\mathrm{NC}$ & $1.05 \pm 1.03$ & $1.92 \pm 1.33$ & $1.50 \pm 1.54$ & $2.57 \pm 1.32$ & NS \\
\hline NB & $0.06 \pm 0.14$ & $0.53 \pm 0.38$ & $0.12 \pm 0.30$ & $1.06 \pm 0.90$ & 1 vs 4,3 vs 4 \\
\hline STT-1 & $0.13 \pm 0.31$ & $0.65 \pm 0.53$ & $0.61 \pm 0.32$ & $0.86 \pm 0.51$ & 1 vs 4 \\
\hline STT-2 & $1.24 \pm 0.58$ & $2.63 \pm 1.42$ & $2.01 \pm 1.45$ & $3.91 \pm 0.56$ & 1 vs 4,3 vs 4 \\
\hline STT-3 & $3.15 \pm 0.54$ & $3.79 \pm 0.85$ & $3.59 \pm 1.19$ & $4.41 \pm 0.60$ & NS \\
\hline STH & $4.39 \pm 0.90$ & $5.59 \pm 1.07$ & $5.22 \pm 0.36$ & $5.85 \pm 1.69$ & NS \\
\hline DH & $5.75 \pm 0.15$ & $5.73 \pm 0.52$ & $5.69 \pm 0.44$ & $5.62 \pm 0.77$ & NS \\
\hline
\end{tabular}

$N S$ not significant 
be attributed to the differences in types or thickness of the flap, wound stability, volume, structural component of the materials (between Mucoderm ${ }^{\circledR}$ and Alloderm ${ }^{\circledR}$ ), and coating conditions of EMD [33, 39-41]. The interaction between the biomaterials and EMD is a primary determining factor influencing downstream cellular behavior and subsequent periodontal regeneration [41-43]. In this regard, PADM used in this study might act as a suitable carrier for EMD. However, the binding and release kinetics could not be examined in the present study since in vitro experiments are necessary for this. Further investigations are therefore needed to clarify this issue.

In the present study, PADM demonstrated good biocompatibility, which might support its rapid revascularization $[13,20]$, and PADM was completely incorporated into surrounding gingival connective tissue without impairing the healing process. Rothamel et al. observed that native dermal non-cross-linked type I/III collagen (Mucoderm ${ }^{\circledR}$ prototype) was almost completely resorbed after 12 weeks in a subcutaneous rat model, and displayed a faster tissue integration and vascularization with no signs of ingrowing inflammatory cells than chemically cross-linked collagen [21]. These findings may be supported by the report that types I, II, and III collagens and collagen-degradation peptides might function as chemotactic stimuli for fibroblasts in vivo and attract these cells to the site of tissue damage [44]. Moreover, STT and STH were greater in the PADM-applied groups than in the CAF group. The results indicate that PADM may increase and maintain the volume of soft tissue in root coverage treatment $[16,19]$. Interestingly, there were no statistically significant differences in STT and STH between the CAF/ PADM and the CAF/EMD groups, and the amounts of STT and STH in the CAF/EMD group were superior to those of the CAF group. These findings are in agreement with the observation that EMD has a positive influence on the increase in gingival thickness in dehiscence-type defects in dogs [24]. Furthermore, these findings are supported by in vitro studies showing that EMD stimulated the proliferation of gingival fibroblasts $[45,46]$, protected gingival fibroblasts from tumor necrosis factor-induced apoptosis [47], and increased extracellular matrix protein production [48] and the level of TGF- $\beta$, which has been reported to facilitate tissue repair and regeneration [49, 50], in gingival and periodontal ligament fibroblasts [51, 52]. Thus, these effects of EMD might enhance the proliferative/maturation phase of soft tissue wound healing [30, 49].

Compared with those of the $\mathrm{CAF} / \mathrm{EMD}$ group, the amounts of NC, NB, STT, and STH were higher in the CAF/EMD/ PADM group, although not statistically significant. Thus, one plausible explanation for the most favorable results in the $\mathrm{CAF} / \mathrm{EMD} / \mathrm{PADM}$ group may be attributable to the aforementioned positive effects of PADM and EMD in this defect model.

However, due to the small number of teeth treated, the obtained results in the present animal study should be interpreted cautiously. Further clinical studies with large sample size including benchmark CAF/CTG treatment are necessary to verify the effects of CAF/EMD/PADM treatment on periodontal healing in the treatment of human gingival recession defects.

\section{Conclusion and clinical relevance}

Within the limitations of the present study, it can be concluded that the combination of CAF/EMD/PADM may promote periodontal regeneration and points to its potential relevance in the treatment of single Miller class II gingival recessions.

Acknowledgments This study was partly supported by Grants-in-Aid for Scientific Research (C) (No. 25463052) from the Ministry of Education, Science, Sports and Culture of Japan. Porcine acellular dermal matrix (PADM: Mucoderm ${ }^{\mathbb{B}}$ ) was provided free of charge by Botiss Dental, Berlin, Germany.

\section{Compliance with ethical standards}

Funding This study was partly supported by Grants-in-Aid for Scientific Research (C) (No. 25463052) from the Ministry of Education, Science, Sports and Culture of Japan.

Conflict of interest The authors declare that they have no competing interests.

Ethical approval The procedures and protocol design described here were approved by the ethical committee of the Animal Research Center of Kagoshima University, Japan (MD13164).

\section{References}

1. Löe H, Anerud A, Boysen H (1992) The natural history of periodontal disease in man: prevalence, severity, and extent of gingival recession. J Periodontol 63:489-495

2. Cheng GL, Fu E, Tu YK, Shen EC, Chiu HC, Huang RY, Yuh DY, Chiang CY (2014) Root coverage by coronally advanced flap with connective tissue graft and/or enamel matrix derivative: a metaanalysis. J Periodontal Res. doi:10.1111/jre12199

3. Hofmänner P, Alessandri R, Laugisch O, Aroca S, Salvi GE, Stavropoulos A, Sculean A (2012) Predictability of surgical techniques used for coverage of multiple adjacent gingival recessionsa systematic review. Quintessence Int 43:545-554

4. Griffin TJ, Cheung WS, Zavras AI, Damoulis PD (2006) Postoperative complications following gingival augmentation procedures. J Periodontol 77:2070-2079

5. Aroca S, Molnár B, Windisch P, Gera I, Salvi GE, Nikolidakis D, Sculean A (2013) Treatment of multiple adjacent Miller class I and II gingival recessions with a modified coronally advanced tunnel 
(MCAT) technique and a collagen matrix or palatal connective tissue graft: a randomized, controlled clinical trial. J Clin Periodontol 40:713-720

6. Harris RJ (1998) Root coverage with a connective tissue with partial thickness double pedicle graft and an acellular dermal matrix graft: a clinical and histological evaluation of a case report. J Periodontol 69:1305-1311

7. Gapski R, Parks CA, Wang HL (2005) Acellular dermal matrix for mucogingival surgery: a meta-analysis. J Periodontol 76:1814-1822

8. Nuñez J, Caffesse R, Vignoletti F, Guerra F, San Roman F, Sanz M (2009) Clinical and histological evaluation of an acellular dermal matrix allograft in combination with the coronally advanced flap in the treatment of Miller class I recession defects: an experimental study in the mini-pig. J Clin Periodontol 36:523-531

9. Moslemi N, Mousavi Jazi M, Haghighati F, Morovati SP, Jamali R (2011) Acellular dermal matrix allograft versus subepithelial connective tissue graft in treatment of gingival recessions: a 5-year randomized clinical study. J Clin Periodontol 38:1122-1129

10. Henderson RD, Greenwell H, Drisko C, Regennitter FJ, Lamb JW, Mehlbauer MJ, Goldsmith LJ, Rebitski G (2001) Predictable multiple site root coverage using an acellular dermal matrix allograft. J Periodontol 76:1814-1822

11. Cummings LC, Kaldahl WB, Allen EP (2005) Histologic evaluation of autogenous connective tissue and acellular dermal matrix grafts in humans. J Periodontol 76:178-186

12. Carney CM, Rossmann JA, Kerns DG, Cipher DJ, Ress TD, Soloman ES, Rivera-Hidalgo F, Beach MM (2012) A comparative study of root defect coverage using an acellular dermal matrix with and without a recombinant human platelet-derived growth factor. J Periodontol 83:893-901

13. Pabst AM, Happe A, Callaway A, Ziebart T, Stratul SI, Ackermann M, Konerding MA, Willershausen B, Kasaj A (2014) In vitro and in vivo characterization of porcine acellular dermal matrix for gingival augmentation procedures. J Periodontal Res 49:371-381

14. McGuire MK, Scheyer ET (2010) Xenogeneic collagen matrix with coronally advanced flap compared to connective tissue with coronally advanced flap for the treatment of dehiscence-type recession defects. J Periodontol 81:1108-1117

15. Cardaropoli D, Tamagnone L, Roffredo A, Gaveglio L (2012) Treatment of gingival recession defects using coronally advanced flap with a porcine collagen matrix compared to coronally advanced flap with connective tissue graft: a randomized controlled clinical trial. J Periodontol 83:321-328

16. Jepsen K, Jepsen S, Zucchelli G, Stefanini M, de Sanctis M, Baldini N, Greven B, Heinz B, Wennström J, Cassel B, Vignoletti F, Sanz M (2013) Treatment of gingival recession defects with a coronally advanced flap and a xenogeneic collagen matrix: a multicenter randomized clinical trial. J Clin Periodontol 40:82-89

17. Molnar B, Aroca S, Keglevich T, Gera I, Windisch P, Stavropoulos A, Sculean A (2013) Treatment of multiple adjacent Miller class I and II gingival recessions with collagen matrix and the modified coronally advanced tunnel technique. Quintessence Int 44:17-24

18. Sculean A, Mihatovic I, Shirakata Y, Bosshardt DD, Schwarz F, Iglhaut G (2015) Healing of localized gingival recessions treated with coronally advanced flap alone or combined with either a resorbable collagen matrix or subepithelial connective tissue graft. A preclinical study. Clin Oral Investig 19:903-909

19. Fick1 S, Nannmark U, Schlagenhauf U, Hürzeler MB, Kebschull M (2014) Porcine dermal matrix in the treatment of dehiscence-type defects - an experimental split-mouth animal trial. Clin Oral Implants Res. doi:10.1111/clr12355

20. Pabst AM, Lehmann KM, Walter C, Krüger M, Stratul SI, Kasaj A (2014) Influence of porcine-derived collagen matrix on endothelial progenitor cells: an in vitro study. Odontology Dec 9

21. Rothamel D, Benner M, Fienitz T, Happe A, Kreppel M, Nickenig HJ, Zöller JE (2014) Biodegradation pattern and tissue integration of native and cross-linked porcine collagen soft tissue augmentation matrices - an experimental study in the rat. Head Face Med. doi:10. 1186/1746-160X-10-10

22. Hammarström L, HeijlL L, Gestrelius S (1997) Periodontal regeneration in a buccal dehiscence model in monkeys after application of enamel matrix proteins. J Clin Periodontol 24:669-677

23. HeijlL L, Heden G, Svardström G, Östgren A (1997) Enamel matrix derivative (Emdogain ${ }^{\mathbb{R}}$ ) in the treatment of intrabony periodontal defects. J Clin Periodontol 24:705-714

24. Al-Hezaimi K, Al-Fahad H, O’Neill R, Shuman L, Griffin T (2012) The effect of enamel matrix protein on gingival tissue thickness in vivo. Odontology 100:61-66

25. Mellonig JT (1999) Enamel matrix derivative for periodontal reconstructive surgery: technique and clinical and histologic case report. Int J Periodontics Restorative Dent 19:8-19

26. Araũjo MG, Lindhe J (1998) GTR treatment of degree III furcation defects following application of enamel matrix proteins. J Clin Periodontol 25:524-530

27. Shirakata Y, Taniyama K, Yoshimoto T, Miyamoto M, Takeuchi N, Matsuyama T, Noguchi K (2010) Regenerative effect of basic fibroblast growth factor on periodontal healing in two-wall intrabony defects in dogs. J Clin Periodontol 37:374-381

28. Hoang AM, Klebe RG, Steffensen B, Ryu OH, Simmer JP, Cochran DL (2002) Amelogenin is a cell adhesion protein. J Dent Res 81: 497-500

29. Schlueter SR, Carnes DL, Cochran DL (2007) In vitro effects of enamel matrix derivative on microvascular cells. J Periodontol 78: $141-151$

30. Miron RJ, Dard M, Weinreb M (2014) Enamel matrix derivative, inflammation and soft tissue wound healing. J Periodontal Res. doi: $10.1111 /$ jre 12245

31. Lee EJ, Meraw SJ, Oh TJ, Giannobile WV, Wang HL (2002) Comparative histologic analysis of coronally advanced flap with and without collagen membrane for root coverage. J Periodontol 73:779-788

32. Sallum EA, Casati MZ, Caffesse RG, Funis LP, Nociti Júnior FH, Sallum AW (2003) Coronally positioned flap with or without enamel matrix protein derivative for the treatment of gingival recessions. Am J Dent 16:287-291

33. de Oliveira CA, Spolidório LC, Cirelli JA, Marcantonio RA (2005) Acellular dermal matrix allograft used alone and in combination with enamel matrix protein in gingival recession: histologic study in dogs. Int J Periodontics Restorative Dent 25:595-603

34. Suaid FF, Carvalho MD, Santamaria MP, Casati MZ, Nociti Jr FH, SallumAW SEA (2008) Platelet-rich plasma and connective tissue grafts in the treatment of gingival recessions: a histometric study in dogs. J Periodontol 79:888-895

35. Al-Hezaimi K, Rudek I, Al-Hamdan KS, Javed F, Iezzi G, Piattelli A, Wang HL (2013) Efficacy of acellular dermal matrix and coronally advanced flaps for the treatment of induced gingival recession defects: a histomorphometric study in dogs. J Periodontol 84:1172-1179

36. Windisch P, Sculean A, Klein F, Tóth V, Gera I, Reich E, Eickholz P (2002) Comparison of clinical, radiographic, and histometric measurements following treatment with guided tissue regeneration or enamel matrix proteins in human periodontal defects. J Periodontol 73:409-417

37. Fujita T, Yamamoto S, Ota M, Shibukawa Y, Yamada S (2011) Coverage of gingival recession defects using guided tissue regeneration with and without adjunctive enamel matrix derivative in a dog model. Int J Periodontics Restorative Dent 31:247-253

38. Haney JM, Nilveus RE, McMillan PJ, Wikesjö UME (1993) Periodontal repair in dogs: expanded polytetrafluoroethylene barrier membranes support wound stabilization and enhance bone regeneration. J Periodontol 64:883-890 
39. Wikesjö UM, Sigurdsson TJ, Lee MB, Tatakis DN, Selvig KA (1995) Dynamics of wound healing in periodontal regenerative therapy. J Calif Dent Assoc 23:30-35

40. Fickl S, Kebschull M, Schupbach P, Zuhr O, Schlagenhauf U, Hürzeler MB (2011) Bone loss after full-thickness and partialthickness flap elevation. J Clin Periodontol 38:157-162

41. Miron RJ, Bosshardt DD, Hedbom E, Zhang Y, Haenni B, Buser D, Sculean A (2012) Adsorption of enamel matrix proteins to a bovinederived bone grafting material and its regulation of cell adhesion, proliferation, and differentiation. J Periodontol 83:936-947

42. Ziegler J, Mayr-Wohlfart U, Kessler S, Breitig D, Günther KP (2002) Adsorption and release properties of growth factors from biodegradable implants. J Biomed Mater Res 59:422-428

43. Woo KM, Chen VJ, Ma PX (2003) Nano-fibrous scaffolding architecture selectively enhances protein adsorption contributing to cell attachment. J Biomed Mater Res A 67A:531-537

44. Postlethwaite AE, Seyer JM, Kang AH (1978) Chemotactic attraction of human fibroblasts to type I, II, and III collagens and collagen-derived peptides. Proc Natl Acad Sci U S A 75:871-875

45. Zeldich E, Korean R, Nemcovsky C, Weinreb M (2007) Enamel matrix derivative stimulates human gingival fibroblast proliferation via ERK. J Dent Res 86:41-46

46. Keila S, Nemcovsky CE, Moses O, Artzi Z, Weinreb M (2004) In vitro effects of enamel matrix proteins on rat bone marrow cells and gingival fibroblasts. J Dent Res 83:134-138
47. Zeldich E, Korean R, Dard M, Nemcovsky C, Weinreb M (2007) Enamel matrix derivative protects human gingival fibroblasts from TNF-induced apoptosis by inhibiting caspase activation. J Cell Physiol 213:750-758

48. Haase HR, Bartold PM (2001) Enamel matrix derivative induces matrix synthesis by cultured human periodontal fibroblast cells. $\mathrm{J}$ Periodontol 72:341-348

49. Faler BJ, Macsata RA, Plummer D, Mishra L, Sidawy AN (2006) Transforming growth factor-beta and wound healing. Perspect Vasc Surg Endovasc Ther 18:55-62

50. Rodrigues TL, Marchesan JT, Coletta RD, Novaes Jr AB, Grisi MF, Souza SL, Taba Jr M, Palioto DB (2007) Effects of enamel matrix derivative and transforming growth factorbeta 1 on human periodontal ligament fibroblasts. J Clin Periodontol 34:514-522

51. Van der Pauw MT, Van den Bos T, Everts V, Beertsen W (2000) Enamel matrix-derived protein stimulates attachment of periodontal ligament fibroblasts and enhances alkaline phosphatase activity and transforming growth factor beta1 release of periodontal ligament and gingival fibroblasts. J Periodontol 71:31-43

52. Okubo K, Kobayashi M, Takiguchi T, Takada T, Ohazama A, Okamatsu Y, Hasegawa K (2003) Participation of endogenous IGF-I and TGF-beta 1 with enamel matrix derivative-stimulated cell growth in human periodontal ligament cells. J Periodontal Res 38:1-9 